\title{
Overcoming Challenges and Boundaries Through the Innovation of University Learning and Teaching Practices
}

\author{
Elena Luppi, Lucia Balduzzi, Nicolò Cavina, and Carla Salvaterra
}

\section{Premises}

Our universities today embody the outcome of a long transition of higher education institutions from environments for intellectual selection to engines of democratization, social promotion and widespread innovation (Biggs and Tang 2011; Trow 2007). Universities are tasked nowadays with increasing the knowledge and skills of a population whose schooling rates are growing progressively and whose training needs are becoming more and more complex. They are called upon to respond to current cultural, social and economic challenges and, above all, to the challenges of tomorrow, in a constantly changing scenario. For the above-mentioned reasons, university curricula are increasingly incorporating issues related to citizenship education or citizenship, since the great challenge of the transition from local to global, understood as plural, is a priority (Owens et al. 2018; Aydin 2014). Moreover, work environments require professionals who have deep disciplinary knowledge but, at the same time, high transversal skills needed for adaptation and innovation (Wheat et al. 2018).

This perspective requires strong academic coordination between the different actors involved in learning processes: university management-for the definition of policies, strategies and organizational models; teaching staff_called to self-reflect and innovate their practices-and students, who play the leading role in learning.

\footnotetext{
E. Luppi $(\varangle) \cdot$ L. Balduzzi $\cdot$ N. Cavina $\cdot$ C. Salvaterra

University of Bologna, Bologna, Italy

e-mail: elena.luppi@unibo.it 


\section{Innovation in Teaching and Learning as a Dynamic Strategy}

Innovation in teaching and learning within our institutions will require a plan of strategic actions for innovation: our view is, and taking inspiration from the formative educational evaluation research (Scriven 2003), that these could be based on three levels of intervention:

- Level A actions: Action Research Activities: A strategic view on teaching innovation will profit from a sound scientific base, systematic data collection and research activities, aimed at engaging the teaching and administrative support staff in participatory activities of analysis and collective reflection, identification of the training needs and implementation of the consequent training actions useful for future redesign, also experimenting techniques of video analysis to support teachers in the reflection and redesign of the didactics.

- Level B actions: Specific training paths through innovative methodologies: Transversal actions, connected to the qualifications of university teaching and learning, may be aimed at raising awareness of the whole teaching staff to the quality of teaching through a series of transversal actions, addressing the development of competencies related to the "Organizational Citizenship Behaviours" (Organ 1988) and aimed at introducing training on transversal competencies for students.

- Level C actions: Design of an organizational model to support innovation and for the quality of teaching: The quality of teaching and learning should be supported by a dedicated organizational structure making the implementation possible of the system for innovation described above. Quality management is understood as a managerial approach to the intentional development of the conditions and skills that are necessary for constant improvement. The synergy between all these levels and processes is guaranteed through quality assessment actions, accompanied by training interventions, in the logic of "formative assessment".

\section{Innovation in the National Context: Teacher Training}

Teacher training, in Italy as in many countries, represents a typical field of strong national regulations and frequent regulatory interventions that make it difficult to create stable training paths over time and therefore long-term experimentation.

Today's scenarios require universities to provide training courses for initial and in-service teachers who must cope not only with the acquisition of disciplinary and teaching skills that comply with national school regulations and systems. They must also acquire new skills to face new global challenges. We are referring not only to soft skills, on which all curricula at universities and schools are progressively concentrating efforts but also to competencies that are fundamental today such as education 
for active citizenship, education for social and environmental sustainability, requiring multi and interdisciplinary approaches and training. In regard to these fields, the most promising scenarios will be shaped by the construction of national and international networks. These networks will also, thanks to the many important strategic partnerships and alliances funded by international programmes like the Erasmus+ and H2020 programme in Europe, to design participatory action and advocacy processes. This type of intervention is particularly important in countries like Italy today, not only for the qualification of educational and instructional paths, but also to support the visibility and social prestige of the work of teachers and, more generally, of humanistic and scientific culture, which do not enjoy great social recognition in all countries. Among the societal challenges faced by education, we now have to cope with the issue of training new citizenship skills for sustainable development in a society increasingly influenced by scientific and technological development. Public engagement, as well as science education, together with ethics, gender and governance, also require transversal attention and new research efforts. Those topics are objects of interdisciplinary research and need further investment in order to become an object of not only cultural but also didactic methodological approach within teacher training programmes, planned through strong collaboration between education sciences and other disciplines, for the implementation of innovative actions and the dissemination of good practices in the school sector.

\section{Impacting in the Local Context: Innovating Lifelong Learning and Continuing Education}

Promoting, supporting, and effectively making lifelong learning opportunities available is crucial for further establishing and consolidating the university mission in a rapidly evolving technological scenario and in a world increasingly characterized by cultural diversity, migrations, centralization of wealth, with access to higher education becoming more and more based on the economic situation of the individual and his or her social status (Crossan et al. 2004).

Lifelong learning is one of the central elements of the educational and training mission of most universities that are investing to make the lifelong learning and continuing education offer structural and diversified. This approach is analyzed below in two specific areas, apparently very different but which respond in a complementary way to the needs of inclusion, increased job opportunities and active participation in civil society: corporate education, or technical and vocational training, and prison university programmes. 


\subsection{Corporate Education}

The process of redefining the methodology with which to design, organize and deliver training to company employees starts with the definition of the main objectives to be achieved:

- Answering requests and anticipating needs of higher professional education from companies, stakeholders, institutions;

- Strengthening relations with industrial partners;

- Ensuring uniformity of design, support services, and delivery of corporate education (including standard costs);

- Establishing a data collection system that allows for the monitoring of training needs of companies and the universities in terms of offer.

As regards in particular the first element, it has been found that one of the main needs of companies today is to invest in training for their employees by implementing solutions aimed at increasing internal skills, speeding up professional growth and expanding knowledge in new sectors and technological fields, involving staff on several levels (e.g. basic courses for a wide audience, advanced courses for specific profiles, alignment for new hirees).

Two procedural models, which, according to our experience, are most effective, can be identified and put in place. The first one is characterized by a medium- to long-term scope, which provides for the setting-up of a series of courses, possibly repeatable, co-designed with company management. Such a model is implemented through a multi-year renewable agreement with the industrial partner and the creation of a coordination committee, responsible for co-designing the educational offer. Specific contracts are then signed to put in place the individual training courses, awarding credits to the students-employees through a system of continuing education units. The second model is instead designed to provide timely and typically shortterm training, commissioned by the industrial partner with the university, which goes the way of bridging specific skill-gaps of its employees.

The benefits that derive from this structured and systematic approach are manifold:

- Consolidation of the university's vocation to interact with the local community, through the transfer of innovative knowledge to companies, fostering growth and producing positive effects on the economic-social system;

- Development of innovative teaching methods and strengthening the ability to respond to varying training needs;

- Integration of the university's educational offer, both generalized and "tailormade";

- Strengthening of university-industry interaction impacting on multiple areas. 


\subsection{Prison University Programmes}

Penitentiary university centres and prison colleges are for some universities a long tradition, for others a recent development, but in both cases reaffirming an HEI's aspiration to fully guarantee access to study as an inalienable right of the human being by providing higher education to prisoners. Since public universities have the duty to provide ways and means for this right to be potentially realized, a network of university penitentiary programmes has gradually developed throughout Italy over the last 20 years. The main objective is to expand quality higher education opportunities for incarcerated people and to foster the values of equity, civic engagement, independence of thought, and freedom of expression.

The University of Bologna Penitentiary Programme was one of the first to be established in Italy, and now there are 33 structures nationwide based on the same model, serving 74 penitentiaries. Based on our experience in this field, we think this will be an area of promising exchange for innovative practices to improve educational experiences within universities. A peculiar innovation concerns the involvement of students in cooperative work with their colleagues who attend courses from inside the prison. Innovative forms of "service learning", that is, a learning-by-doing experience with a social purpose can be an area for improving meaningful experiences and sharing within the university community and among universities. Another aspect that is worth noting in this context, in terms of "lessons learned" and innovative teaching, is certainly the need for teachers to develop new educational methods that, while being compatible with logistical constraints, are effective in adult training and oriented first of all towards individual empowerment, thanks not only to fostering creative learning, but also to improving employment opportunities once the learner has completed his or her prison sentence, and engaging in the intellectual challenge towards knowledge and culture, especially for those who are serving lengthy or life sentences.

\section{Concluding Remarks}

Innovation does not happen by simply applying innovative methods or tools, but requires high skills for investigating learning environments, assessing students' needs, fostering motivation and innovating daily in order to choose the methods that can provide the best answers to the current learning challenges in the most diverse contexts.

This article has presented, very briefly, some reflections arising from the system of innovation of university teaching and learning processes that the University of Bologna is experiencing. The model is based on research and, in particular, on assessment and evaluation in its formative sense, where data collection allows for a continuous monitoring of the teaching actions and the consequent redesign, according to the learning needs. The model is designed to promote interventions that have an impact on all actors and the actions that can improve teaching and learning processes, with the ultimate aim of increasing student skills and participation. 
Moreover, we have put forward views in three areas of typical national and local contexts (developments in school education, corporate education and penitentiary programmes) in which universities can play a fundamental role.

As we hope to have shown in all these very localized contexts the global commitment of HEIs towards educational values and improved access to tertiary education, the exchange of innovative practices and networking of universities within international projects, can significantly improve impact in local societies and create positive change at a global level. Universities are increasingly at the heart of innovation, not only in research and knowledge but also in education, training, teaching and learning for citizenship.

\section{References}

Aydin, O. T. (2014). Current developments and trends in higher education. Journal of Business Economics and Finance, 3(4).

Biggs. J., \& Tang. C. (2011). Teaching for quality learning at university. Maindenhead, UK: SRHE and Open University Press.

Crossan, B., Gallacher, J., Osborne, M. (2004). Researching Widening Access to Lifelong Learning: Issues and Approaches in International Research, Routledge, ISBN 978-0415322362

Organ, D. W. (1988). Organizational citizenship behavior: The good soldier syndrome. Lexington Books/DC Heath and Com.

Owens, M. T., Trujillo, G., Seidel, S. B., Harrison, C. D., Farrar, K. M., Benton, H. P. \& Byrd, D. T. (2018). Collectively improving our teaching: attempting biology department-wide professional development in scientific teaching. CBE—Life Sciences Education, 17(1), ar2.

Scriven, M. (2003). Evaluation theory and metatheory. In International handbook of educational evaluation (pp. 15-30). Springer, Dordrecht.

Trow, M. (2007). Reflections on the transition from elite to mass to universal access: Forms and phases of higher education in modern societies since WWII. In International handbook of higher education (pp. 243-280). Springer, Dordrecht.

Wheat, C. A., Sun, Y., Wedgworth, J. C., \& Hocutt, M. M. (2018). Active University Teaching and Engaged Student Learning: A Mixed Methods Approach. Journal of the Scholarship of Teaching and Learning, 18(4), 28-50.

Elena Luppi is Rector's Delegate for Innovation in Teaching and Learning at the University of Bologna and has been Rector's Delegate for Gender Equality in the same university. She is Associate Professor in Educational Research at the University of Bologna at the Department of Education Studies.

Lucia Balduzzi is professor at the Department of Education Studies "Giovanni Maria Bertin", and Director of First Cycle Degree of Educator in childhood Social Services at the University of Bologna.

Nicolò Cavina is Full Professor of Internal Combustion Engines and Hybrid Powertrains at the University of Bologna. In 2002 he founded, with three colleagues, Alma Automotive srl, a spinoff company of the University of Bologna. Since then, he has served as member of the board and vice-president. 
Carla Salvaterra is assistant professor at the Department of History and Cultures at the University of Bologna. She was Vice-Rector for International Relations at the University of Bologna from 2009 to 2015.

Open Access This chapter is licensed under the terms of the Creative Commons Attribution 4.0 International License (http://creativecommons.org/licenses/by/4.0/), which permits use, sharing, adaptation, distribution and reproduction in any medium or format, as long as you give appropriate credit to the original author(s) and the source, provide a link to the Creative Commons license and indicate if changes were made.

The images or other third party material in this chapter are included in the chapter's Creative Commons license, unless indicated otherwise in a credit line to the material. If material is not included in the chapter's Creative Commons license and your intended use is not permitted by statutory regulation or exceeds the permitted use, you will need to obtain permission directly from the copyright holder. 